\title{
Desenvolvimento de produtos e inovações produtivas em empresas de construção de edifícios
}

Márcio Minto Fabricio Doutor em Engenharia e Professor do Departamento de Arquitetura e Urbanismo da Escola de Engenharia de São Carlos - Universidade de São Paulo - marcio@sc.usp.br

\begin{abstract}
RESUMO
Este artigo aborda o processo de desenvolvimento de novos produtos na indústria de construção de edifícios. É caracterizado de forma genérica o processo de desenvolvimento de produto praticado nessa indústria e é desenvolvido um estudo de caso em empresa de construção e incorporação que se destaca pela introdução de inovações nos seus produtos e processos. Concluindo, é analisado o processo de desenvolvimento de produto que permitiram à empresa estudada implementar diferentes tipos de inovações em seus empreendimentos.
\end{abstract}

Palavras-Chaves: Desenvolvimento de Produto. Projetos de Edifícios. Construção e Incorporação de Edifícios. 
O Processo de Desenvolvimento de Produto (PDP) pode ser definido como uma série de atividades organizadas com o objetivo de transformar necessidades em conceitos e estes em produtos tangíveis (Machado; Toledo, 2008).

O PDP compreende as atividades de projeto do produto e de seu processo de produção, envolvendo a formulação do programa de necessidades, a concepção e desenvolvimento das características formais, funcionais e técnicas do produto, projeto e planejamento dos meios de produção necessários e acompanhamento do desempenho do produto em uso.

Para Back et al. (2008) o desenvolvimento de produto é um processo de transformação e geração de informações e deve ser efetuado por uma equipe multidisciplinar, envolvendo diferentes profissionais com formações complementares.

Ulrich e Eppinger (2004) discorrem sobre a duração de um PDP, afirmando que uma minoria de produtos pode ser desenvolvida em tempo inferior a um ano. Em geral este tempo varia entre três e cinco anos, podendo-se chegar a dez anos para que o processo esteja completo, em alguns casos.

Para o desenvolvimento de um novo produto devem ser considerados o conhecimento tecnológico disponível, as necessidades e demandas do mercado, da sociedade e as questões culturais envolvidas.

O desenvolvimento de produto também se relaciona com o posicionamento competitivo das empresas, situando-se na interface entre a empresa e o mercado. Cabendo ao desenvolvimento de produtos identificarem e desenvolverem soluções para as demandas dos clientes e usuários (Toledo, 1993).

A gestão do processo de desenvolvimento de produto nas empresas em geral tem acompanhado as evoluções organizacionais e os paradigmas de gestão empregados na produção industrial. Assim, em acordo com o paradigma de produção industrial taylorista - fordista, que apregoa a idéias de divisão social e especialização do trabalho (estudo científico do trabalho) e a separação entre atividades de produção e gerenciais, o desenvolvimento de novos produtos foi fragmentado entre projetar e executar, e, progressivamente, os projetos vão envolvendo a participação de mais projetistas em funções especializadas, concorrem nesse sentido, também, a crescente complexidade dos produtos e a necessidade de soluções de projeto de maior complexidade tecnológica. Nesse contexto, a gestão do processo de desenvolvimento de novos produtos tende a ser estruturada de forma especializada, hierárquica, organizada seqüencialmente (Womack et al. 1990).

$\mathrm{Na}$ construção civil esse processo seqüencial também se verifica, com a agravante de que a maior parte dos projetos e consultorias especializadas é desenvolvida por empresas de projeto terceirizadas, conformando equipes bastante heterogêneas e dispersas (Fabricio, 2002; Romano, 2003).

Como resultado desse processo tem-se, num projeto tradicional de edifício, uma pequena interatividade entre as especialidades de projeto e grande dificuldade para coordenar projetos e fomentar decisões multidisciplinares.

Com a disseminação do paradigma de produção flexível ou de produção enxuta as atividades de fluxo (interação entre funções) e o conceito de valor agregado ganham destaque nas estratégias de produção e o projeto é cada vez mais observado como 
etapa prioritária na agregação de valor aos produtos (Koskela, 1992). O desenvolvimento de novos produtos passa a ser compreendido como uma atividade cuja interatividade é fundamental para qualidade do produto e para eficiência do processo produtivo (Koskela; Ballard; Tanhunpää, 1997).

Nesse contexto o PDP pode ser compreendido como conjunto de teorias e abordagens de gestão para o processo de concepção e desenvolvimento de novos produtos cuja filosofia principal é a integração entre áreas funcionais, entre especialidades envolvidas no projeto e integração entre projeto do produto e projeto da produção, com uma visão focada no ciclo de vida (Rozenfed et al., 2006).

Particularmente importante segundo a literatura é a integração do PDP com as estratégias e capacidades produtivas das empresas e seu posicionamento no mercado.

$\mathrm{Na}$ atividade de construção e incorporação de edifícios, embora a visão tradicional predomine é possível encontrar empresas líderes que desenvolvem novas organizações de PDP voltadas a ampliar a eficiência desse processo e à qualidade do ciclo de vida dos edifícios. Nesse artigo, será desenvolvido um diagnóstico da prática tradicional de desenvolvimento de produto no ambiente da indústria de construção e incorporação de edifícios e posteriormente será apresentado um estudo de caso em empresa desse setor que vem inovando seus produtos e na própria forma de gestão de seu processo de desenvolvimento de produto.

\section{CARACTERÍSTICAS DO PRODUTO EDIFÍCIO}

Conforme destaca Silva (1996) os produtos gerados na indústria de construção de edifícios são bens de consumo duráveis que se destinam ao uso (habitação, comercio, indústria, equipamentos públicos, etc.) e ao investimento.

Os edifícios são caracterizados por sua singularidade, grande tamanho, elevado valor, e longa vida útil. Além disso, trata-se de um produto com elevada importância social e econômica. Outra particularidade do edifício é a inserção urbana que confere a este tipo de produtos um caráter único dentro das estruturas produtivas e de consumo da sociedade, uma vez parte substancial da qualidade dos edifícios é determinada pela sua localização urbana (Tahon, 1997).

A indústria de construção de edifícios é bastante heterogênea, contemplando diferentes modalidades de organização produtiva e formas de comercialização de seus produtos (edifícios). Assim, por exemplo, quando uma empresa encomenda a construção de uma nova planta fabril ou prédio de escritórios temos uma construção sob encomenda privada, quando o governo licita um novo edifício público temos uma construção sob encomenda pública. Quando o futuro morador de uma residência contrata os projetistas e gerência a obra, temos uma modalidade de autopromoção do empreendimento.

Nesse artigo, será abordada a produção de edifícios verticais privados destinados a habitações numa modalidade de produção denominada de construção e incorporação em que uma empresa construtora compra ou incorpora um terreno, contrata e gerência os projetos (desenvolvidos por escritórios de projetistas especializados), constrói e comercializa o empreendimento.

Trata-se de um arranjo bastante difundido no país e tem como característica a presença da empresa de construção e incorporação como promotora e gestora de 
todas as etapas do empreendimento o que, ao menos em tese, permite uma maior integração do processo de desenvolvimento de novos produtos.

Nessa modalidade, os processos produtivos são organizados segundo ciclos intermitentes em que a unidade de produção é o empreendimento composto por um ou mais edifícios agrupados em um mesmo terreno.

A demanda por novos empreendimentos edificações é altamente variável e complexa, influenciada pela localização e entorno urbano do empreendimento, pela conjuntura econômica, pela disponibilidade de financiamento, etc., marcando um mercado altamente variável em relação ao volume de produção.

Pelo lado qualitativo, as dinâmicas sociais e urbanas atreladas às mudanças no comportamento, usos e costumes das pessoas têm exigido adaptações do espaço construído para atender às novas necessidades e hábitos de moradia, de trabalho, de lazer, e, principalmente, do marketing imobiliário que, de quando em quando, promove novos equipamentos condominiais como mote para venda de edifícios (playgraud, sala de ginástica, cozinha goumet, etc). Também são verificadas constantes mudanças ligadas a acabamentos, fachadas e estilos arquitetônicos.

Com relação à conformação dos arranjos espaciais das plantas das unidades e volumetria dos edifícios verificam-se variações quanto às áreas e quantidade de cômodos (maior numero de quartos, salas e banheiros, com áreas cada vez menores) nos quais predominam um arranjo tradicional de organização da habitação baseado num sistema de tripartição entre espaços íntimos (quartos e estares), espaços sociais (salas) e espaços de serviços (lavanderia e cozinha) que vêm da habitação burguesa francesa do século XIX (Tramontano, 2006).

Para responder à singularidade do produto e necessidade de adaptação do mesmo ao sitio urbano (terreno) e às novas demandas dos clientes, a indústria de construção se notabiliza pelo constante ciclo de produção de novos empreendimentos, ou seja, a cada novo terreno desenvolve-se um produto sob medida às suas características climáticas, topográficas, geológicas e, principalmente, à situação urbana (padrão econômico do bairro, proximidade de escolas, equipamentos de saúde, comercio, etc.).

A complexidade de cada produto e de cada processo de produção de edifício caracteriza uma "indústria de protótipos", organizada para produção de produtos únicos e diferenciados (Amorim, 1996).

A singularidade de uma "indústria de protótipos" exige a articulação de processos produtivos específicos nos quais a unidade básica da atividade produtiva são os empreendimentos imobiliários. Assim, o processo de produção do setor de construção está centrado nos empreendimentos individuais para os quais convergem, projetos especificamente desenvolvidos, materiais e componentes fornecidos pela indústria de matérias de construção, e serviços subcontratados de empreiteiras especializadas em subsistemas do edifício (execução e montagem de fôrmas, execução de estrutura, de alvenarias, de instalações hidráulicas, instalações elétricas, pintura, etc.).

Os empreendimentos de construção demandam um grande tempo de execução (meses ou anos), mas suas estruturas produtivas (o canteiro de obras) se configuram de forma temporária na medida em que o sistema de produção é montado para dar conta da construção de um determinado empreendimento e se desfaz após o término deste. 
Quanto ao processo de produção, o empreendimento de construção é bastante dinâmico e sua organização e seus intervenientes vão se transformando ao longo de sua execução, à medida que a obra se desenvolve passando, simplificadamente, por etapas de fundação, estruturas, vedações externas e internas, cobertura, instalações e acabamentos, cada qual com necessidades específicas de mão de obra, equipamentos, e insumos materiais.

De acordo com Melhado (1999), os empreendimentos de construção são organizados em quatro fases principais: a montagem da operação; o projeto; a execução e a entrega; o uso, operação e manutenção do edifício. Estas fases são desenvolvidas de forma hierárquica e fragmentadas, envolvendo a participação encadeada de diferentes agentes do processo de desenvolvimento e produção do edifício.

Conforme observa Bobroff (1998) esta organização faz crer que o processo produtivo do setor é organizado por empreendimentos, entretanto as práticas setoriais demonstram uma clara dualidade em que a montagem do negócio e a concepção do produto (atividades de promoção e projeto) são desenvolvidas de forma particular e orientadas a cada novo produto, enquanto na obra as soluções construtivas e organizacionais tendem a ser padronizadas, embora a produção não seja seriada e os processos não sejam necessariamente racionalizados.

\section{O DESENVOLVIMENTO DE PRODUTO NA CONSTRUÇÃO E INCORPORAÇÃO DE EDIFÍCIOS}

O PDP de um edifício pode ser definido como o conjunto de atividades necessário para seu projeto desde a identificação das oportunidades dos mercados até as especificações dos requisitos e características a serem entregues aos clientes (Tzortzopoulos, 2004).

Tradicionalmente na indústria de construção e incorporação de edifícios, a concepção de novos empreendimentos é associada aos projetos de arquitetura e engenharia civil que representam os desenvolvimentos conceituais, espaciais e tecnológicos dos edifícios. Na prática o desenvolvimento de novos produtos é percebido nesse setor como os projetos de produto. Mas, de fato, muitas atividades com caráter de concepção, seleção de alternativas e desenvolvimento de idéias são exercidas em outras fases do empreendimento, por diversos agentes do processo de produção, sem uma maior integração desses processos com o processo de projeto do produto.

A montante dos projetos de arquitetura e engenharia, a montagem do empreendimento e incorporação do terreno, a contratação dos projetistas, a definição do programa de necessidades e a estratégia de marketing envolvem uma série de decisões e formulações que representam uma atividade fundamental no desenvolvimento de um novo produto imobiliário. Essas atividades são desenvolvidas principalmente pelo empreendedor, ocasionalmente com a participação do arquiteto e com pouca interação com os demais membros da equipe de projeto.

$\mathrm{Na}$ outra ponta, durante a realização das obras, uma série de decisões, detalhamentos e planejamentos são desenvolvidos de forma a permitir a tradução e a complementação das especificações dos projetos de produto em soluções construtivas. 
Para desenvolver esses projetos de edifícios são montadas equipes de projeto compostas por diferentes projetistas, vinculadas a empresas de projetos distintas e contratadas pelo promotor para atuarem no desenvolvimento de um determinado empreendimento. Conta-se com um número relativamente grande de projetistas, algo entre cinco a dez profissionais, mas conforme o porte e a complexidade do empreendimento esse número pode ser consideravelmente maior (Quadro 1).

Quadro 1 - Principais especialidades e serviços de projeto de edifícios. Fonte: Melhado et al. (2005)

\begin{tabular}{|c|l|}
\hline TIPOS DE PROJETOS & \multicolumn{1}{|c|}{ ESPECIALIDADES E SERVIÇOS DE PROJETO DE EDIFÍCIOS } \\
\hline Arquitetura & $\begin{array}{l}\text { Arquitetura; Paisagismo; Luminotécnica; Conforto térmico; Interiores; Comunicação visual; } \\
\text { etc. }\end{array}$ \\
\hline Estrutura & $\begin{array}{l}\text { Contenções; Fundações; Superestrutura - concreto armado ou protendido (moldado in loco ou } \\
\text { pré-fabricado), aço, madeira, estruturas mistas, alvenaria estrutural, entre outras. }\end{array}$ \\
\hline Instalações Hidrossanitárias & $\begin{array}{l}\text { Hidráulicas - água fria e água quente; Prevenção e combate a incêndio; Esgotamento } \\
\text { sanitário e águas pluviais/drenagem; Fluidos - gás; aquecimento; exaustão, etc. }\end{array}$ \\
\hline Instalações Mecânicas & $\begin{array}{l}\text { Transporte vertical - Elevadores, monta-cargas; Transporte horizontal e vertical - escadas e } \\
\text { esteiras rolantes; Ar condicionado; Cozinha Industrial; etc. }\end{array}$ \\
\hline Instalações Elétricas & Instalações Elétricas; centrais de medição, transformador de rebaixamento de tensão. \\
\hline Instalações Eletrônicas & $\begin{array}{l}\text { Telefonia; Comunicação e dados (redes); Vídeo, Áudio e Sonorização; Acústica; Segurança } \\
\text { patrimonial; Automação predial; etc. }\end{array}$ \\
\hline Consultorias & $\begin{array}{l}\text { Custos; Orçamento; Racionalização construtiva; Análise crítica de estruturas; Análise crítica } \\
\text { de instalações. (Interagem com os projetos do produto e os projetos para produção) }\end{array}$ \\
\hline Projeto para Produção & $\begin{array}{l}\text { Fôrmas das Estruturas de Concreto; Vedações verticais; Fachadas; Esquadrias e caixilhos; } \\
\text { Laje racionalizada; armação; revestimento cerâmico; revestimento monocamada; } \\
\text { revestimento de argamassa; Impermeabilização; etc. }\end{array}$ \\
\hline
\end{tabular}

O prazo de desenvolvimento de um novo empreendimento de edifício é bastante variável, conforme a complexidade do produto e a disponibilidade de recursos do promotor. Em geral o tempo relacionado com a montagem do empreendimento e projeto, incluindo aprovações junto às prefeituras e órgãos competentes, varia entre seis meses a dois anos, e o tempo de construção varia de dois a quatro anos, considerando empreendimentos imobiliários típicos, podem, evidentemente, sofrer grandes variações.

Dentre os fatores externos que determinam o prazo de projeto pode se destacar a obtenção de licenças e aprovações oficiais que podem ser bastante demoradas, principalmente em empreendimentos de maior porte que envolvem impactos e licenças ambientais. Já as obras podem ser bastante influenciadas pela velocidade de vendas das unidades na planta (a partir do projeto), e são bastante condicionadas pela conjuntura econômica e pelo acesso a linhas de financiamento de longo prazo.

Ao longo do processo de desenvolvimento de produto, vários projetistas, consultores e agentes do empreendimento são mobilizados para contribuir no projeto. Cada agente participa com os seus interesses e conhecimentos de forma a desenvolver uma parte das decisões e formulações projetuais.

Esses projetistas terceirizados se organizam em pequenos escritórios e prestam serviços especializados de projeto (projeto de arquitetura, estruturas, fundações, instalações elétricas e hidráulicas, etc.) para diferentes construtoras e clientes simultaneamente. 
Nesse processo verificam-se diferentes interfaces entre os principais envolvidos, e diferentes compatibilizações são necessárias para garantir a coerência entre as decisões e projetos.

Primeiramente é contratado o arquiteto que efetivamente concebe um produto que posteriormente será complementado pelos projetos de engenharia. Muitas vezes, a concepção arquitetônica é terminada sem nenhuma participação formal dos demais projetistas, salvo algumas consultas ao projetista de estruturas que costuma entrar no processo de projeto antes das demais especialidades de engenharia.

O processo se configura dessa forma como seqüencial e hierárquico, possibilitando apenas ao projetista de arquitetura tomar contado direto com a montagem e elaboração do programa de necessidades do empreendimento. Os demais projetistas partem do projeto ou anteprojeto de arquitetura e das soluções adotadas nesta disciplina para desenvolver soluções técnicas que "complementam" o projeto de arquitetura.

Embora seja mais forte com relação ao projeto de arquitetura, é possível verificar, ao longo de todo o processo de projeto, uma hierarquização em que os projetistas a jusante do processo tomem contato com o programa e com os projetos a montante por meio de soluções projetuais desenvolvidas e não por meio dos problemas tratados.

Outra particularidade da indústria da construção é que os empreendimentos são lançados à venda no mercado antes da sua conclusão - "venda na planta". Isso permite que, em muitos casos, essa venda se inicia apenas com um projeto básico aprovado nos órgãos reguladores (aprovação do denominado "projeto legal"), após o qual uma série de desenvolvimentos, principalmente relacionados às especificações técnicas dos edifícios têm que ser complementados (Figura 2).

Com isso, em muitos empreendimentos, a mobilização dos projetistas ocorre de forma gradual à medida que o processo de lançamento no mercado demonstra a viabilidade econômica do empreendimento. Tal prática, por um lado, amplia a flexibilidade das empresas que podem abortar novos projetos em curso, sem ter mobilizado a totalidade dos recursos necessários ao seu desenvolvimento. Por outro lado, limita a interatividade entre os projetos uma vez que especificações contratuais prévias têm que ser respeitadas independente da sua adequação aos junta as diferentes especialidades de projeto envolvidas.

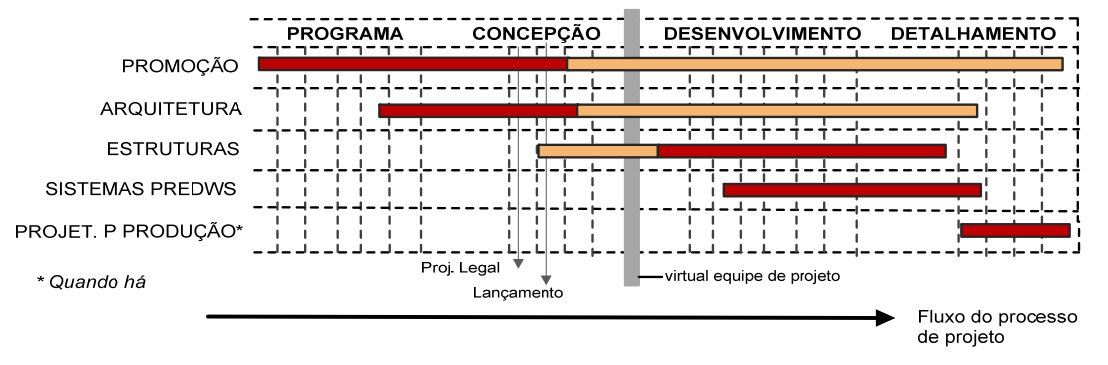

de acordo com Fabricio ; Melhado (2001)

Figura 1 - Esquema genérico de um processo seqüencial de desenvolvimento do projeto de edifícios participação dos agentes ao longo do processo. Fonte: Fabricio; Melhado (2001). 
No estágio atual da indústria, predomina uma organização seqüencial e fragmentada de desenvolvimento de novos produtos em que, por um lado, o desenvolvimento de um empreendimento é claramente dividido em etapa de montagem da operação imobiliária (promoção do empreendimento), projetos arquitetônicos, projetos técnicos de engenharia do produto e, por fim, desenvolvimento e planejamento da produção (planejamento de obra e construção).

Nesse processo fragmentado e seqüencial, a possibilidade de colaboração entre projetistas é bastante reduzida e a proposição de modificações por um projetista de determinada especialidade implica a revisão de projetos já mais amadurecidos de outras especialidades, significando enormes re-trabalhos ou até mesmo o abandono de projetos inteiros.

Além disso, uma segunda cisão importante no PDP na construção ocorre entre a etapa do projeto do produto e o projeto para produção.

Sem preocupação com o sistema de produção da construtora, os projetos do produto terceirizados restringem-se, normalmente, a fornecer informações sobre 0 produto (forma, dimensões, etc.) sem entrar em detalhes de como e em qual seqüência produzir; além de, muitas vezes, como destaca Franco (1992), não possuem um nível de detalhamento e integração adequados, que esclareçam todas as características e interfaces do produto.

Segundo o diagnóstico de Farah (1996), a tendência na construção tradicional é tratar os projetos como responsáveis pelas indicações da forma e das características tecnológicas do edifício e não de sua produção. Para a autora, o projeto é visto como um projeto de produto sem indicações de como produzi-lo e, muitas vezes, não caracteriza completamente o produto, deixando para a etapa de obra a definição de características do produto e a seleção de materiais ou componentes a serem utilizados.

A participação das construtoras, subempreiteiros, fornecedores de materiais e usuários na elaboração dos projetos é, ainda, bastante limitada.

Assim, enquanto em muitas indústrias o projeto para produção ou projeto para montagem é parte integrada do processo de desenvolvimento de produto, na construção faltam projetos executivos detalhados e uma participação efetiva das construtoras e subempreiteiros da obra durante o processo de projeto do edifício.

Em síntese, os processos de projeto mais tradicionais acabam sendo orientados para a definição do produto sem considerar adequadamente a forma e as implicações quanto à produção das soluções adotadas. Além disso, é comum que as especificações e detalhamentos de produto sejam incompletas, falhas e incompatíveis e acabem tendo que ser modificadas ou resolvidas durante a obra, quando a equipe de produção decide sobre características e especificações do edifício não previstas em projeto.

\section{ESTUDO DE CASO}

O estudo de caso aborda uma empresa de construção e incorporação de edifícios quanto ao seu processo de desenvolvimento de produto, considerando principalmente a integração entre desenvolvimento de novos produtos e as estratégias de produção da empresa. 
O estudo de caso foi realizado em São Paulo, SP e, embora não esgota e nem representa o universo de desenvolvimento de edifícios paulistanos, dão idéia da complexidade e limitações de práticas inovadoras na indústria de construção, particularmente no segmento de construção e incorporação de edifícios.

O caso, apresentado neste artigo, foi selecionado com base na relevância da empresa do ponto de vista de inovações técnico-produtivas praticadas no mercado no período da investigação. O trabalho de campo foi desenvolvido entre meados de 2003 e meados de 2005 envolvendo o departamento de projeto e a diretoria técnica da empresa.

A coletada de dados junto à empresa estudada consistiu de entrevistas junto ao gerente de projetos da empresa e com projetistas que atuaram como contratados pela empresa, envolvendo contatos com o diretor técnico da empresa, visita à sede da empresa e acompanhamento do trabalho de coordenação de projetos. Bem como, visitas às obras de quatro empreendimentos da empresa, análise documental junto a projetos desenvolvidos pela empresa, e o desenvolvimento de dois workshops entre o gerente de projeto da empresa e alunos de uma disciplina de pós-graduação.

O principal foco de análise desse estudo é a integração entre o processo de desenvolvimento de produto da empresa e a introdução de inovações tecnológicas e produtivas nas obras de construção de edifícios. Também foi investigado e caracterizados as inovações nos produtos e em que medida essas inovações foram suportadas por PDP inovadores e mais integrados.

A Empresa estudada é relativamente nova, tendo iniciado como empresa de incorporação de edifícios em 1990 e como construtora e incorporadora em 1993.

Para estruturar seus processos de produção e de desenvolvimento de produto, a empresa foi buscar no mercado profissionais de larga experiência de atuação no setor, cabendo a estes estruturar os processos da empresa. O fato da empresa ser nova e dispor de significativos recursos materiais e humanos, provavelmente, permitiu aos profissionais experientes e gabaritados contratados maior liberdade na proposição de soluções e práticas inovadoras, que seriam barradas ou teriam mais dificuldades de serem aceitas em estruturas produtivas mais tradicionais e consolidadas.

A empresa atuava em vários seguimentos de mercado (condomínios residenciais, comerciais e hotéis), sendo analisado, recorte do estudo de caso, sua atuação em empreendimentos de construção e incorporação de edifícios habitacionais.

Em geral, os empreendimentos de construção e incorporação desenvolvidos pela empresa eram destinados ao público de classe média - alta e eram situados em regiões nobres da cidade.

A empresa apresentava uma estratégia de produção e opções construtivas relativamente diferenciada das práticas encontradas no mercado, privilegiando soluções de produto e especificações de projeto que otimizassem a etapa de construção.

A empresa adotou, nos condomínios residências, estruturas de concreto armado moldadas in-loco, com solução de paredes exteriores maciças (pouco usuais no Brasil), pilares centrais de concreto de médio / alto desempenho e lajes planas nervuradas (Figura 2). Em alguns edifícios comerciais também foram desenvolvidas soluções em estrutura metálica (pilar e laje), com fechamento externo em painéis pré-fabricados de concreto e laje steel-deck, propiciando uma ainda maior rapidez nos prazos de obra.

Essas opções tecnológicas tinham como meta eliminar interferências entre subsistemas construtivos de forma a aumentar a produtividade, simplificar 0 
planejamento e a atuação das equipes de trabalho e, conforme o empreendimento, ampliar a velocidade das obras e reduzir seu prazo de entrega. De fato, as opções de projeto e a organização da produção permitiram a empresas obter índices de produtividade (segundo dados da própria empresa) comparáveis a produtividade verificada na construção de edifícios norte americana (Instituto McKinsey, 2000).
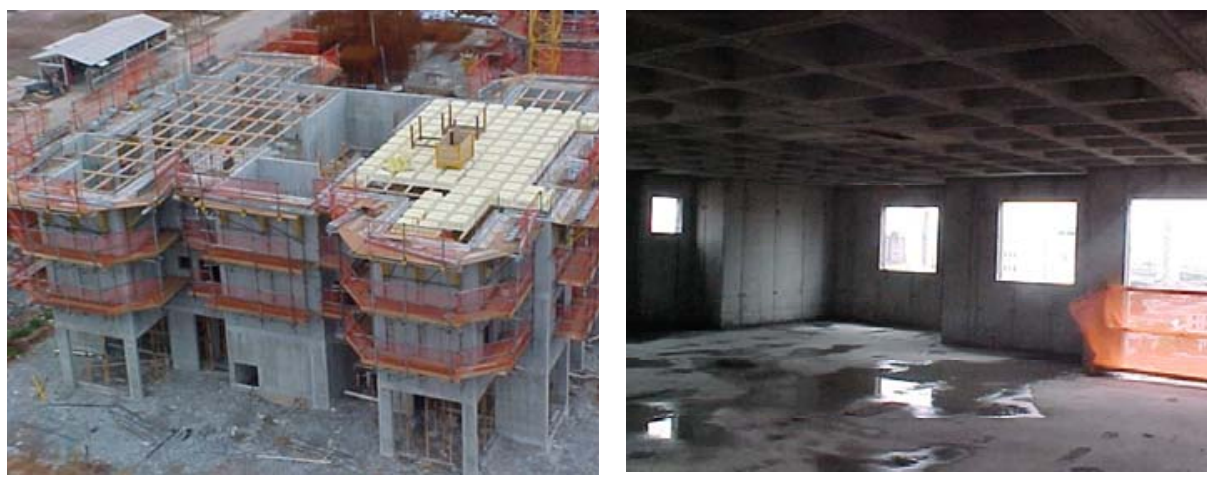

Figura 2 - Sistema construtivo da empresa estudada (visão externa e interna). Fotos: Waltermino Jr.

Do ponto de vista da interface com o mercado, essas opções tecnológicas buscaram atender demandas tais como utilizar grandes vãos entre pilares, laje nervurada e fechamento interno de gesso acartonado de forma a propiciar maior flexibilidade aos clientes, através da possibilidade de escolha entre diversas opções de planta, além de diminuir a densidade de pilares nos subsolos (estacionamentos) de forma a maximizar a oferta de vagas, atributo bastante valorizado no mercado paulistano de edifícios.

Para as instalações elétricas a empresa privilegiou o uso de soluções inovadoras com a utilização de sistemas de barramento blindados tipo "bus-way", medição remota de energia, sim
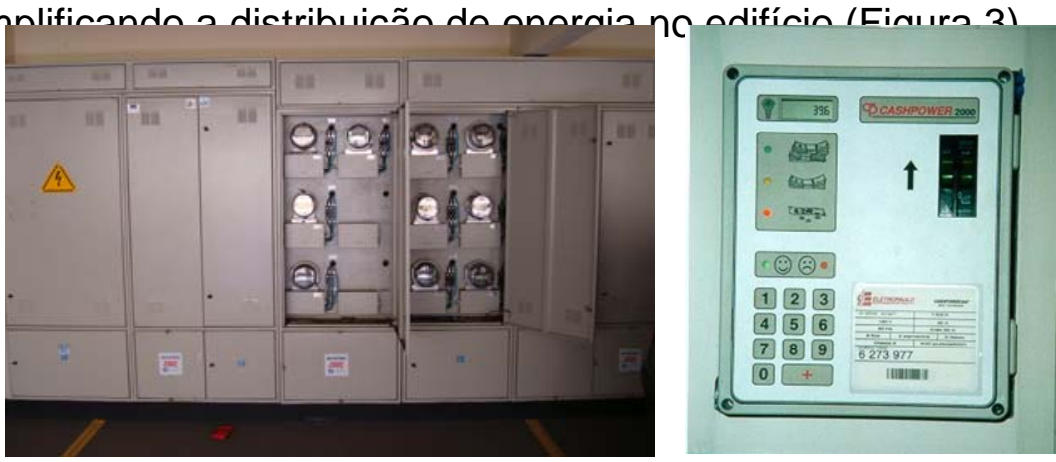

Figura 3 - Bateria de medidores de energia no térreo (solução convencional) e medidor eletrônico dentro do apartamento. Fotos: Autor e Waltermino Jr. (2004).

Esse tipo de inovação na construção é um processo complexo que envolve a interação entre diversos agentes da cadeia produtiva. O sistema de medição remota demanda a participação integrada dos órgãos reguladores, de empresas fornecedoras de materiais e componentes e da concessionária pública de distribuição de energia. 
O coração dessa inovação é o desenvolvimento da micro-eletrônica e das telecomunicações que permitem a utilização de um medidor eletrônico que funciona através de uma senha, fornecida pela concessionária mediante 0 pagamento antecipado de uma cota de energia num sistema similar ao dos telefones celulares prépagos. Para tanto foi necessário a concessionária criar um serviço de telemática de venda de energia que funciona vinte quatro horas por dia.

No sistema convencional, os medidores eletromecânicos devem ficar no térreo do edifício, em um local que permita o acesso do funcionário que fará a leitura para a concessionária. No novo sistema, a medição ocorre de forma remota, eliminando as visitas mensais dos funcionários de medição e reduzindo a necessidade de espaço no térreo para medidores.

Essa inovação, além de simplificar e baratear a operação da concessionária de energia, eliminar os problemas de inadimplência e corte de energia, uma vez que o sistema é pré-pago, permite uma grande simplificação nas instalações elétricas do edifício.

No sistema convencional, devido à necessidade de posicionar os medidores no térreo e a partir daí caminhar com um eletroduto para cada unidade de consumo, são demandados grandes shafts para passagem de várias prumadas de eletrodutos, exigindo grandes caixas de passagens nas áreas comuns dos andares, grande altura de entre-forros para caminhamento horizontal dos eletrodutos no térreo.

Com o sistema de medição remota é possível distribuir a energia até os apartamentos de forma concentrada utilizando trabalhando com uma única prumada blindada de dimensão muito menor que o conjunto dos eletrodutos, permitindo uma grande simplificação no sistema de distribuição condominial.

Depois de distribuída a energia até os apartamentoes, internamente as unidades, foram utilizados eletrodutos passando por dentro das paredes de gesso acartonado e entre-forros (espaço entre a laje nervurada de concreto e forro de gesso) de forma a evitar a necessidade de posicionamento de caixas de passagem e eletrodutos previamente a concretagem da laje, minorando interferências entre os subsistemas de laje e de instalações elétrica e evitando a necessidade de sobreposição das equipes de montagem de laje com a equipe de elétrica que ocorre na construção convencional (Figura 4).
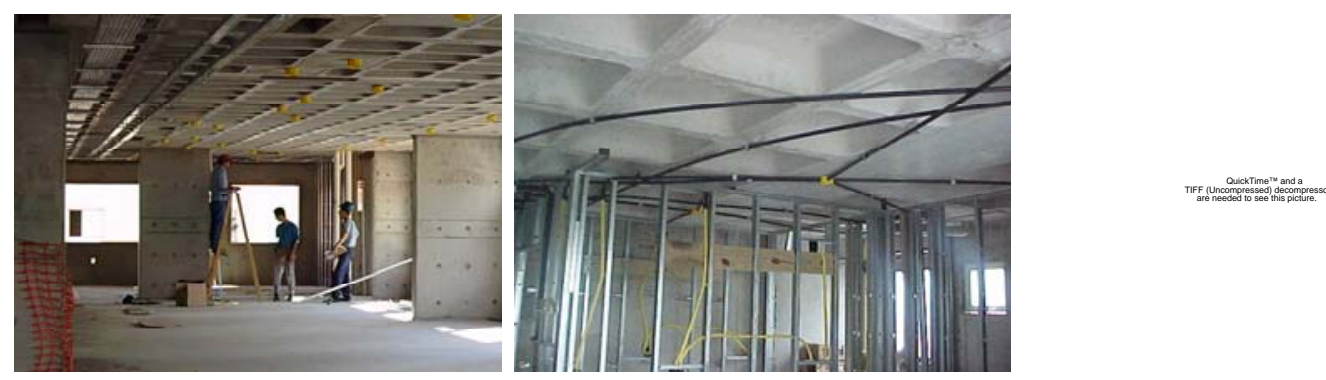

Figura 4 - Passagem de eletrodutos e vedações internas em paredes de gesso acartonado em obras da empresa estudada. Fotos: Waltermino Jr. 
Para as instalações hidráulicas foram adotadas tubulações flexíveis - PEX que juntamente com as instalações sanitárias eram alocadas em shafs verticais visitáveis e entre-forros na horizontal, de forma a evitar a passagens de tubulações embutidas nas paredes, solução que elimina o retrababalho e os desperdícios da solução convencional de se abrir rasgos nas alvenarias para passagens de tubulações e facilita o processo manutenções e reparos (Figura 5).

Seguindo a premissa de evitar interferência entre subsistemas e entre equipes de produção, foi eliminado da fase de execução das lajes o posicionamento de aberturas para passagem de tubulações das bacias sanitárias, sendo essas executadas posteriormente pela equipe de instalação com auxílio de furadeira de cerra - copo para concreto.
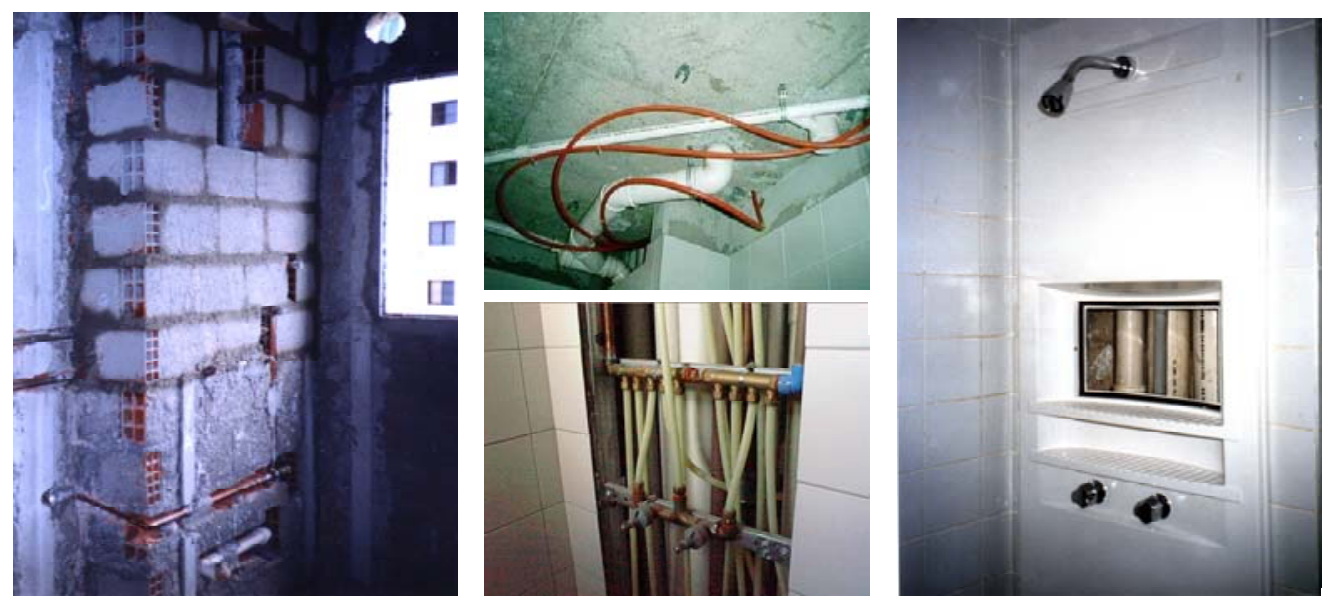

Figura 5 - Solução convencional de distribuição de água fria versus solução em tubulação flexível (PEX) e shafts visitável. Fotos: Autor e Waltermino Jr.

Com esse tipo de soluções não convencionais a empresa buscava ampliar a produtividade do trabalho no canteiro de obras e eliminar desperdícios através de uma clara estratégia de racionalização e industrialização das construções alicerçadas em um principio de tornar independentes as etapas das obras, eliminando interferências entre equipes de trabalho.

Em acordo com esse princípio a empresa utilizava-se de empreiteiros terceirizados cujo contrato previa a execução de todo um subsistema (estruturas, vedações em gesso acartonado, instalações elétricas instalações hidráulicas, etc.), envolvendo às vezes o próprio fornecimento dos materiais necessários. Dessa forma, a empresa se caracteriza segundo Silva (2004) como uma "gerenciadora de obras".

A cada empreiteiro ou "sistemista" eram alocados em uma área no canteiro de obras onde estes deveriam desenvolver seus almoxarifados e pequenas centrais de produção, bem como estoques quando estes não eram distribuídos junto aos locais de utilização - principio just in time.

Assim, a maior parte do trabalho era realizada por equipes de empresas contratadas e o pessoal da própria construtora se encarregava da segurança, acompanhamento e controle e gerenciamento da obra. Para ilustrar, em uma das obras 
visitadas, se verificou em torno de duzentos operários terceirizados trabalhando simultaneamente, para uma equipe aproximadamente de quinze pessoas da própria empresa, a maioria com funções gerenciais.

No tocante aos projetos às soluções de produção adotadas implicavam em inúmeras diretrizes fornecidas pela empresa construtora aos projetistas contratados, que deveriam desenvolver soluções compatíveis com a tecnologia que a empresa privilegiava. Isso implicava em parcerias entre empresa e diversos projetistas uma vez que as soluções adotadas exigiam um treinamento e adaptação das soluções de projeto para atender à empresa. Essas parcerias foram particularmente verificadas quanto aos projetistas de especialidades técnicas (principalmente engenheiros).

No caso da contratação do projetista de arquitetura, embora também se verificasse uma certa constância de alguns arquitetos como projetistas de várias obras da empresa, era privilegiado, para seleção e contratação do arquiteto, a aceitação do nome deste no mercado, considerando a "tendência" e os "estilos" arquitetônicos em voga no mercado.

Assim, apesar de soluções construtivas inovadoras, a empresa desenvolvia produtos com aparência e forma pautados pelos estilos arquitetônicos da "moda" e com planta e disposição espacial dos cômodos em acordo com o modelo de tripartição funcional tradicional no mercado de edificações habitacionais brasileiro.

A estratégia de eliminar interferências entre equipes de produção colocava aos projetistas a necessidade de soluções mais bem coordenadas a fim de prever as interfaces entre subsistemas, demandado uma maior interatividade entre projetista de diferentes especialidades e, também, acarretava mudanças no fluxo de detalhamento dos projetos.

Assim, a estratégia de produção adotada pela empresa condicionava de forma determinante uma série de especificações e soluções de projeto e balizavam a resolução de algumas interfaces entre subsistemas, exigindo um processo constante de coordenação, compatibilização e checagem dos projetos.

A coordenação entre os projetistas envolvidos era delegada a um único coordenador de projetos funcionário do departamento de projetos da construtora, sendo que na época da pesquisa, havia três funcionários (dois arquitetos e um engenheiro) desempenhando essa função na empresa. Esses coordenadores atuavam tanto na fase de projeto do produto, como também, eram responsáveis por transmitir os projetos à obra, acompanhar a obra e eventuais necessidades de readequações nos projetos e realização da atualização da documentação de projeto (projeto "as built").

Conforme a complexidade do empreendimento, também era contratado um profissional externo para ajudar na checagem e compatibilização dos desenhos e soluções dos diversos projetos, mas estes tinham atuação restrita à fase de projeto do produto.

A troca de informações entre projetistas, envolvendo desenhos em CAD e memoriais de projetos em outros formatos de arquivo digitais era auxiliada por um sistema de colaboração centralizado em um web de gerenciamento de projeto (extranet de projetos) contratado de um fornecedor especializado no mercado de construção.

Através desse sistema, todos os arquivos de projetos deveriam ser introduzidos (up load) e ficavam disponíveis para os demais projetistas envolvidos, através de senhas e permissões específicas. O sistema também facilitava o coordenador de projetos na tarefa de gerenciamento prazos e as troca de informações entre os 
projetistas, contando com ferramentas de acompanhamento de cronograma e registro de inserções e consultas. Ao final, o projeto ficava arquivado no repositório (data center do sistema extranet contratado) e o acesso era liberado à obra que através do sistema obtinham as cópias atualizadas dos projetos e, quando necessário, demandavam direto ao bureau as cópias impressas necessárias.

Com relação ao fluxo de projetos, a empresa desenvolveu um fluxograma referencial para desenvolvimento de seus produtos que era adaptado pelo coordenador do projeto para cada novo empreendimento. Esse fluxograma estava balizado pelos escopos das especialidades de projetos e era subdividido segundo o grau de maturidade das soluções, com gates de validação das fases, em geral, atrelados as reuniões da equipe de projetistas que conforme a etapa e o empreendimento podiam ocorrer de forma presencial ou através da ferramenta web de gerenciamento de projeto.

Essa sistemática de interação entre os projetistas tinha início após o anteprojeto arquitetônico e a montagem e o estudo de viabilidade do empreendimento, ou seja, não considerava a escolha do terreno e não contemplava a primeira fase da concepção do produto, mantendo parte importante do processo de desenvolvimento de produto fragmentado.

$\mathrm{Na}$ outra ponta, na interface entre projeto e obra, o fluxo considerava algumas atividades ligadas ao projeto para produção das obras que dessa forma faziam parte do processo de desenvolvimento do produto e contribuíam para ampliar a construtibilidade das obras.

De fato, a adoção de algumas opções tecnológicas / construtivas, tais como utilizar elementos pré-fabricados, fundir paredes monolíticas de concreto com função de estrutura e vedação externa, exigiam que desde o início o projeto levasse em conta essas soluções e as múltiplas interferências, tais como detalhamento de vão de caixilho junto com o desenvolvimento da solução estrutural.

Por outro lado, o uso de divisões internas de gesso acartonado, instalações visitáveis escondidas por bancadas, carenagens, forros, shafts, privilegiar furações em laje ao invés de marcação de furos antes da concretagem, possibilitavam que uma vez desenvolvida a solução global, alguns detalhamentos de projeto pudessem ser postergados para os momentos finais da fase de projeto e até mesmo pudessem ser tomadas com a obra em execução, sem implicar em desperdícios e re-trabalhos.

Por exemplo, uma vez definida as prumadas de elétrica e hidráulica, a definição final de pontos de luz e tomada e o tipo de bacia e seu exato posicionamento podiam ser postergados, já que as instalações necessárias seriam todas instaladas por divisórias de gesso acartonado ou entreforro.

Essa possibilidade de postergar detalhamentos além de dar folga ao cronograma de projetos, possibilitava também ampliar a flexibilidade na venda de unidades, cujo layout seria definido pelos clientes com base em uma ampla gama de possibilidades de planta.

\section{CONCLUSÕES}

No setor de construção de edifícios co-habitam diferentes práticas de organização, gerenciais e de integração do processo de desenvolvimento de novos produtos. 
É comum, no setor, empresas que desenvolvem produtos (edifícios) de maneira fragmentada, com os projetos sendo realizados por projetistas terceirizados de forma pouco interativa, mas também existem empresas que desenvolvem produtos inovadores e utilizam práticas mais estruturadas de gestão do processo de desenvolvimento de seus produtos.

O caso apresentado demonstra a existência de inovações nas práticas e produtos gerados pela indústria da construção e as conseqüentes adaptações e aprimoramentos no PDP praticado pela indústria, ilustrando a possibilidade e pertinência de novos modelos para gestão e organização do processo de desenvolvimento de produtos no setor.

A empresa estudada desenvolveu uma estratégia de inovação tecnológica e ampliação da produtividade, buscando através dos projetos e especificações de produto eliminar sobreposições entre os subsistemas construtivos e simplificar a etapa de obra.

De fato, a introdução de práticas construtivas inovadoras demandou novas estratégias de organização do fluxo de projetos e da gestão de seus agentes (projetistas) e, principalmente, a introdução de tecnologia inovadora na construção de edifícios demandou uma maior integração entre projeto e a obra (integração projeto do produto - projeto da produção) e entre estratégias gerenciais e tecnologias construtivas.

Para tanto, a empresa desenvolveu uma estratégia de parcerias junto aos seus fornecedores de projeto (principalmente os projetistas das disciplinas mais técnicas e especializadas). As parcerias praticadas eram unidirecionais, com as construtoras impingindo especificações e cadernos de projeto que deveriam ser seguidos pelos projetistas contratados.

O estudo de caso corroborou a afirmação de Barros (1996) de que "o projeto constitui a 'porta de entrada' para que novas tecnologias sejam efetivadas nos canteiros de obras (...) uma vez que permite incorporar, logo no início do processo de produção, as inovações oriundas dos setores de materiais, de componentes, de equipamentos e de desenvolvimento tecnológico".

Por fim, embora a empresa estudada tenha apresentado avanços nos seus processos de desenvolvimento de produto, é possível afirmar que tais evoluções ocorreram de forma empírica e não se verificou um planejamento sistemático ou uma abordagem integrada do PDP na empresa. Tão pouco houve um estudo ou emprego da literatura e de práticas de outras indústrias para modelagem do PDP praticado, demonstrando a pertinência de modelos de referência próprios para o desenvolvimento de novos empreendimentos de edifícios e as possibilidades de ganho de eficiência para esse processo com uma abordagem mais sistemática e planejada da gestão do processo do PDP na construção de edifícios, bem aponta para a necessidade de desenvolvimento de novas pesquisas e soluções gerenciais de apoio ao processo de projeto nesta indústria.

\section{ABSTRACT}

This paper approaches the development of new products in the building industry. The development process of the product operated in this industry is distinguished in a 
generic way, a study of case about building and real state corporations is being developed, and the case outstand the market by the insertion of innovations at their products and procedures. To conclude it is analysed the development of products procedures which allowed the corporations to apply different types of innovation at their procedures.

Keywords: Product Development. Building Design. Construction. Real Estate and Building.

\section{REFERÊNCIAS}

AMORIM, S.L. Inovações tecnológicas nas edificações: papéis diferenciados para construtores e fornecedores. Gestão \& Produção, São Carlos, v.3, n.3, p.262-73. 1996.

ASSUMPÇÃO, J.F.P. Gerenciamento de empreendimentos na construção civil: modelo para planejamento estratégico da produção de edifícios. 1996. Tese (Doutorado) - Escola Politécnica, Universidade de São Paulo, São Paulo.

BACK, N. et al. Projeto Integrado de Produtos: planejamento, concepção e modelagem. São Paulo: Manole, 2008.

BARROS, M.M.B. Metodologia para implantação de tecnologia construtiva racionalizada na produção de edifícios. 1996. Tese (Doutorado) - Escola Politécnica, Universidade de São Paulo, São Paulo.

BOBROFF, J. Gestion du projet et gestion de la production: une réinterrogation du modèle d'organisation dans la construction en France. In: CONGRESSO LATINOAMERICANO DE TECNOLOGIA E GESTÃO NA PRODUÇÃO DE EDIFÍCIOS: soluções para o terceiro milênio, 1998, São Paulo. Anais... São Paulo: Escola politécnica/USP, 1998. p.21-30.

CARDOSO, F. F. Stratégies d'entreprises et nouvelles formes de rationalisation de la production dans le bâtiment au Brésil et en France. 1996. Tese (Doutorado) École National de Ponts e Chaussées, Paris.

FABRICIO, M. M. Projeto Simultâneo na Construção de Edifícios. 2002. Tese (Doutorado) - Escola Politécnica. Universidade de São Paulo, São Paulo, 2002 308p.

FABRICIO, M. M.; MELHADO, S.B. Desafios para integração do processo de projeto na construção de edifícios. In: WORKSHOP NACIONAL: GESTÃO DO PROCESSO DE PROJETO NA CONSTRUÇÃO DE EDIFÍCIOS, 2001, São Carlos. Anais... São Carlos: EESC/USP, 2001. CD-ROM.

FARAH, M. F. S. Processo de trabalho na construção habitacional: Tradição e 
mudança. São Paulo: Annablume,1996.

FRANCO, L.S. Aplicação de diretrizes de racionalização construtiva para a evolução tecnológica dos processos construtivos em alvenaria estrutural não armada. 1992. Tese (Doutorado) - Escola Politécnica, Universidade de São Paulo, São Paulo.

KOSKELA, L. Application of the new production philosophy to construction. Stanford, Stanford University/CIFE, 1992. (Technical Report, n.72)

KOSKELA, L.; BALLARD, G.; TANHUNPÄÄ, V. Towards lean design management. In: ANNUAL CONFERENCE OF THE INTERNATIONAL GROUP FOR LEAN

CONSTRUCTION, 5., 1997, Gold Coast. Proceedings... Gold Coast: IGLC, 1997. p. 112.

INSTITUTO MCKINSEY. Produtividade no Brasil: a chave do desenvolvimento acelerado. Rio de Janeiro: Campus, 2000.

MACHADO, M.C., TOLEDO, N.N. Gestão do Processo de Desenvolvimento de Produtos. São Paulo: Atlas, 2008.

MELHADO, S. B. O plano da qualidade dos empreendimentos e a engenharia simultânea na construção de edifícios. In: ENCONTRO NACIONAL DE ENGENHARIA DE PRODUÇÃO, 1999, Rio de Janeiro. Anais... Rio de Janeiro: UFRJ/ABEPRO, 1999. CD-ROM.

MELHADO, S.B. et al. Gestão e coordenação de projetos de edifícios. São Paulo: O Nome da Rosa, 2005.

ROMANO, F. V. Modelo de referência para o gerenciamento do processo de projeto integrado de edifícios. 2003. Tese (Doutorado), Universidade Federal de Santa Catarina, Florianópolis.

ROZENFELD, H. et al. Gestão do desenvolvimento de produtos: Uma referência para a melhoria do processo. São Paulo: Saraiva, 2006.

SILVA, M. V. F. P. As atividades de coordenação e gestão do conhecimento nos projetos de edificações. 2004. Dissertação (Mestrado) - Universidade Federal de São Carlos, São Carlos.

SILVA, M. A. C. Metodologia de seleção tecnológica na produção de edificações com emprego do conceito de custos ao longo da vida útil. 1996. Tese (Doutorado) - Escola Politécnica, Universidade de São Paulo, São Paulo.

TAHON, C. Le pilotage simultané d'un projet de construction. Paris: Collection Recherche, 1997. 
TRAMONTANO, M. Apartamentos em São Paulo: brevíssimo exame de uma história controversa.A U. Arquitetura e Urbanismo, v. abril, p. 68-71, 2006.

TOLEDO, J. C. Gestão da mudança da qualidade de produto. 1993. Tese (Doutorado) - Escola Politécnica, Universidade de São Paulo, São Paulo.

TZORTZOPOULOS, $\mathrm{P}$. The design implementation of product development process models in construction companies. 2004. Tese (PhD) - University of Salford, UK, Salford.

WALTERMINO, J. Desenvolvimento de Projetos - InPAR. Palestra apresentada na disciplina de pós-graduação SAP 5879 - Gestão e Coordenação de Projetos - EESCUSP. São Carlos, 04/05/2004. Disponível em <

http://www.eesc.usp.br/sap/disciplinas/SAP5857/Apresentação-InPar.pps> Acessado em 15/05/2007.

WOMACK, J.; JONES, D.; ROOS, D. The machine that changed the world. New York: Rawson Asssociates, 1990.

ULRICH, K.T., EPPINGER, S.D. Product design and development. Boston: McGrawHill/Irwin, 2004. 